\title{
Preparation and assistant-dyeing of formaldehyde-free amphoteric acrylic retanning agent
}

\author{
Jian zhong Ma ${ }^{1,2^{*}}$, Qiwu Liu', Mengxin $\mathrm{Wu}^{2}$ and Zhenhua Tian ${ }^{1 *}$
}

\begin{abstract}
With the enhancement of environmental protection consciousness, concerns have been raised about non-toxic and biodegradable leather retanning agents. According to the European standard 2002/231/EC, the free formaldehyde content of leather products should be less than $150 \mathrm{mg} / \mathrm{kg}$. As one of the retanning agents in the market, the content of free formaldehyde in the Multifunctional retanning agent (MTA) is $372.22 \mathrm{mg} / \mathrm{kg}$ and higher than the limit value. In this work, glutaraldehyde as an alternative of formaldehyde was used to modify acrylic polymer and an amphoteric acrylic retanning agent was prepared. Then it was used in retanning process, and its retanning and assistant-dyeing properties were investigated. The results showed that the free formaldehyde content of amphoteric acrylic retanning agent modified with glutaraldehyde was only $4.17 \mathrm{mg} / \mathrm{kg}$. Meanwhile, the presence of amino groups in the amphoteric acrylic retanning agent improved the dyeing properties of leather by electrostatic attraction. Compared with the leather treated with anionic acrylic retanning agent, the residual dye concentration of the dyeing effluent of the retanned leather with amphoteric acrylic retanning agent decreased from $17.4 \mathrm{mg} / \mathrm{L}$ to $10.0 \mathrm{mg} / \mathrm{L}$, and the dyed leather had better resistances to friction and water-washing. In addition, the $\mathrm{BOD}_{5} / \mathrm{COD}$ value of the wastewater after Mannich base polymer retanning was only 0.32 , indicating that the retanning agent was biodegradable. Moreover, the leather retanned with amphoteric acrylic retanning agent had good thermal stability, fullness and physical and mechanical properties.
\end{abstract}

Keywords: Anionic dye, Acrylic retanning agent, Cationic modification, Free formaldehyde content, Assistant-dyeing

\section{Introduction}

Leather products can be seen in our life everywhere, such as leather shoes, leather handbag and leather sofa. It needs many processes from raw hide to leather products. Among them, retanning, known as "Golden Touch", is the key step that endows leather with sensory quality and different styles [1]. The retanning effect depends mainly on the properties of retanning agent. There are many kinds of retanning agents, among which acrylic polymer retanning agent is the most common [2]. Acrylic polymer retanning agent gives leather

\footnotetext{
*Correspondence: majz@sust.edu.cn; tianzhenhua@sust.edu.cn ${ }^{1}$ College of Bioresources Chemical and Materials Engineering, Shaanxi University of Science \& Technology, Xi'an 710021, Shaanxi, China Full list of author information is available at the end of the article
}

good physical-mechanical properties, light resistance, fullness, softness, fineness and tightness [3, 4]. Moreover, the carboxyl groups on acrylic polymers can coordinately bind with chromium salts in chrome tanned leather $[5,6]$. As a result, the absorption of acrylic polymers improved and the environmental pollution of retanned wastewater reduced.

However, a large number of carboxyl groups in acrylic polymers decrease positive electricity of leather via binding to the amino groups, leading to the reduction of binding sites in leather with anionic dye (commonly used in leather making) [7-10]. Therefore, the dyeuptake rate was affected adversely, and induced non-full color of dyed leather (so-called "color lose" effect) [11].

\section{Springer Open}

(- The Author(s). 2021 Open Access This article is licensed under a Creative Commons Attribution 4.0 International License, which permits use, sharing, adaptation, distribution and reproduction in any medium or format, as long as you give appropriate credit to the original author(s) and the source, provide a link to the Creative Commons licence, and indicate if changes were made. The images or other third party material in this article are included in the article's Creative Commons licence, unless indicated otherwise in a credit line to the material. If material is not included in the article's Creative Commons licence and your intended use is not permitted by statutory regulation or exceeds the permitted use, you will need to obtain permission directly from the copyright holder. To view a copy of this licence, visit http://creativecommons.org/licenses/by/4.0/. 
In order to solve this problem, cationic groups were often introduced into acrylic polymers [12].

There are two main preparation methods of acrylic polymer retanning agent containing cationic groups. First, the direct copolymerization reaction occurs between anionic monomer and cationic monomer. The preparation process of this method is relatively simple, and the product has strong cationic properties. However, the high price of cationic monomers in the market increases the production cost, and the retanning agent is too cationic which is not conducive to the penetration of retanning agent into leather. The latter is actualized via Mannich reaction to introduce cation groups into acrylic polymers. Mannich reaction conditions are mild, and the reaction is easy to control. So Mannich reaction is a relatively good method for the cationic modification of acrylic polymer retanning agent.

Mannich reaction has attracted much attention as a valid method in chemical modification of polymeric molecules [13]. It was extensively reported that acrylamide polymers [14], lignin [15] and proteins [16] were modified by Mannich reaction and then used as retanning agents, flocculants, adhesives, and so on. The polymer modified by Mannich reaction not only maintains its own characteristics, but also gets some special properties due to the charge variation. Mannich reaction is a three-component condensation reaction involving aldehydes, amines and compounds with active hydrogen. In general, an aminomethyl group replaces the active hydrogen atom in this reaction. The resultant condensation product is named as "Mannich base polymer" (Scheme 1).

The active hydrogen component in acrylic polymer for Mannich reaction is usually acrylamide unit. Additionally, our previous work was firstly reported the fact that the carboxylic $\alpha-\mathrm{H}$ of acrylic acid unit also has sufficient activity for Mannich reaction under suitable conditions and then the amphiprotic multifunctional tanning agent (MTA) was successfully prepared by Mannich reaction. This retanning agent not only maintained the good selective fullness, but also improved the dyeing properties of leather $[17,18]$. However, formaldehyde is the most commonly used in Mannich reaction systems for chemical modification of polymer molecules, which has toxicological risks on environment and human and has been listed in the restricted substances $[19,20]$. According to
European Union standard 2002/231/EC, free formaldehyde content of leather products cannot exceed $150 \mathrm{mg} /$ $\mathrm{kg}$ [21]. China also has detailed regulations on the content of free formaldehyde in leather products. The limiting value of free formaldehyde content is as follows: no more than $20 \mathrm{mg} / \mathrm{kg}$ for babies, no more than $75 \mathrm{mg} / \mathrm{kg}$ for products directly contact to skin, no more than $300 \mathrm{mg} / \mathrm{kg}$ products without directly contact to skin. In consideration of human health, the free formaldehyde content of the product should be within the allowable range or eliminated. In recent years, researchers have recognized the problem of free formaldehyde in Mannich reaction, and found that using other aldehydes in Mannich reaction instead of formaldehyde is one feasible method [22].

In authors' previous work, the various aldehyde components of Mannich modified acrylic polymer were screened and they were determined that glutaraldehyde was a reasonable alternative to formaldehyde and participated in Mannich modified acrylic polymer due to its high reactivity. Glutaraldehyde is not only involved in the Mannich reaction, but also cross-linked with the amino groups of collagen. Therefore, Mannich modified acrylic polymer with glutaraldehyde can solve the problem of discoloration and has better retanning performance. The aim of this work was to study on the physicochemical and application properties of the Mannich base polymer synthesized by Mannich reaction with glutaraldehyde, especially the free formaldehyde content and assistant-dyeing properties. Additionally, the thermal properties, physical-mechanical properties and organoleptic properties of leather were examined. Finally, environmental impact assessment of Mannich base polymer was analyzed.

\section{Experimental}

\subsection{Materials}

The wet-blue (chrome tanned) leathers were purchased from Liquan Shunji Leather Industry Co., Ltd. The materials used for leather making were industrial grade except retanning agents, which were prepared by using analytical grade chemicals in the laboratory. The chemicals were purchased as follows: acrylamide (AM), ammonium persulfate and glutaraldehyde (GA, $50 \mathrm{wt} \%$ ) from Tianjin Kemiou Chemical Co., Ltd. (Tianjin, China), acrylonitrile (AN) and acrylic acid (AA) from Tianjin Fuchen Chemical Co., Ltd. (Tianjin, China), sodium

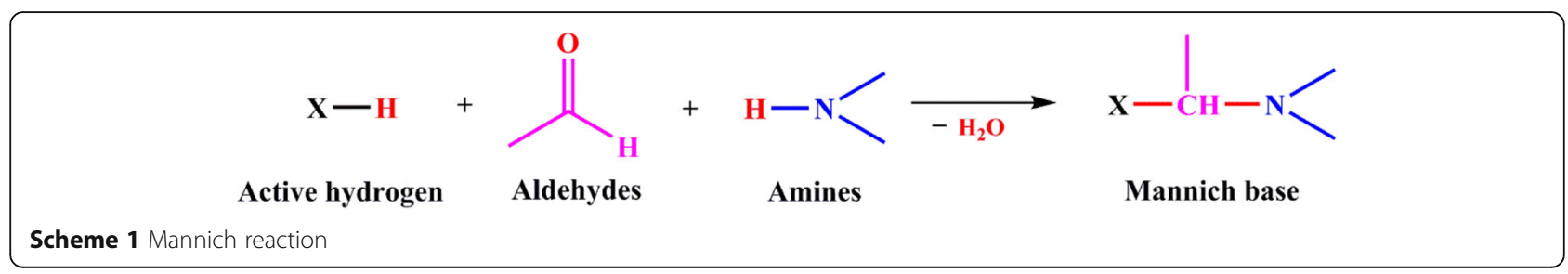


bisulfite from Tianjin Hongyan Chemical Co., Ltd. (Tianjin, China), diethanolamine (DEM) from Guanghua Technology Co., Ltd. (Guangdong, China). GA tanning agent (MTA) was made in our laboratory.

\subsection{Preparation of retanning agent}

\subsubsection{Synthesis of acrylic polymer}

The synthetic route of acrylic polymer (named as P) was presented in Scheme 2. $22.925 \mathrm{~g}$ AA, $2.725 \mathrm{~g}$ AM $(25 \% \mathrm{w} / \mathrm{v}), 5.5 \mathrm{~g} \mathrm{AN}, 12.6 \mathrm{~g}$ sodium bisulfite solution $(40 \% \mathrm{w} / \mathrm{v})$ and $18.1 \mathrm{~g}$ purified water were added into a round-bottom flask $(250 \mathrm{~mL})$ with agitator, thermometer, condenser, and nitrogen gas intake. The mixture was stirred for $15 \mathrm{~min}$ at a certain temperature, and then $5 \mathrm{~g}$ ammonium persulfate $(10 \%$ $\mathrm{w} / \mathrm{v}$ ) as initiator was slowly added dropwise into the four-neck flask. Subsequently, the sample was stirred incessantly $(400 \mathrm{rpm})$ for $4 \mathrm{~h}$ at $45^{\circ} \mathrm{C}$.

\subsubsection{Preparation of Mannich base polymers}

The Mannich base polymer was prepared via the Mannich reaction of $\mathrm{P}$ with aldehydes and amines (Scheme 2). $60 \mathrm{~g} \mathrm{P}$ was firstly added into four-necked round-bottom flask. At $45^{\circ} \mathrm{C}$, the mixture of glutaraldehyde and diethanolamine was subsequently added and stirred for at least $1 \mathrm{~h}$ under the nitrogen condition. After the reaction, $\mathrm{pH}$ of the system was adjusted to $\sim 5.5$ with $40 \%(\mathrm{w} / \mathrm{v})$ sodium hydroxide solution. The obtained Mannich base polymer was named as GAMP.

\subsubsection{Amination degree}

A small amount of Mannich base polymer was deposited by adding anhydrous ethanol, and then the precipitation was again washed with anhydrous ethanol. Finally, the purified precipitation was dried in vacuum at $50^{\circ} \mathrm{C}$ and ground with a mortar. These samples were stored in a desiccator until used.

Puried GAMP (0.1 g) was dissolved in purified water $(10 \mathrm{~mL})$, and $6 \sim 8$ drops of mixed indicator of brominomethol green-methyl red were added. Then the solution was titrated with $0.05 \mathrm{~mol} / \mathrm{L}$ hydrochloric acid standard solution until a pink color appeared; meanwhile, the dosage of hydrochloric acid solution was recorded as $V$. Similarly, a blank experiment was done to record the volume of hydrochloric acid $\left(V_{0}\right)$. The amination degree [23] of the product was calculated according to following formula:

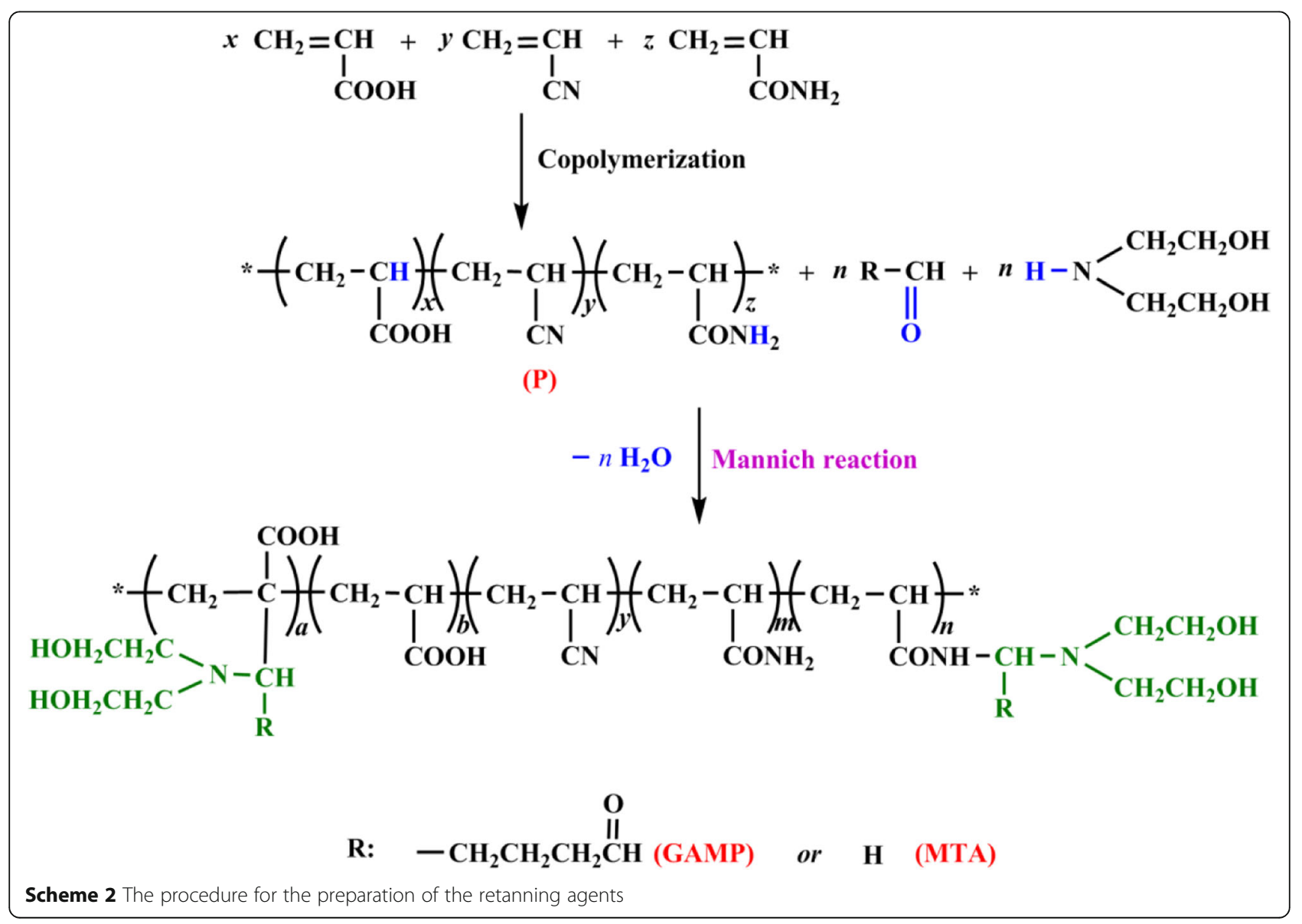




$$
A D(\mathrm{wt} \%)=\frac{M \times 0.05 \times\left(V-V_{0}\right)}{1000 W} \times 100 \%
$$

where $V_{0}$ and $V$ are the consumed volume of hydrochloric acid standard solution for the blank and sample, respectively. $W$ represents the weight of the sample, and $M$ represents the molecular weight of amidation group.

\subsubsection{Proton nuclear magnetic resonance ( ${ }^{1} H$-NMR) spectra}

GAMP, MTA and P were washed several times with absolute ethanol to remove the residual reactants and byproducts, and finally dried by vacuum oven at $60^{\circ} \mathrm{C}$ for $24 \mathrm{~h}$. Then the resultant samples were dissolved in $\mathrm{D}_{2} \mathrm{O}$ with a concentration of $50 \mathrm{mg} / \mathrm{mL}$. The chemical structures of GAMP, MTA and P were determined by ${ }^{1} \mathrm{H}-$ NMR (400 MHz Advance, Bruker, Germany) at $25^{\circ} \mathrm{C}$.

2.2.5 Fourier transform infrared spectroscopy (FT-IR) spectra GAMP, MTA and P were washed several times with absolute ethanol to remove the residual reactants and byproducts, and finally dried by vacuum oven at $60^{\circ} \mathrm{C}$ for $24 \mathrm{~h}$. The sample was uniformly mixed with $\mathrm{KBr}$ and then pressed into a thin slice, which was instantly tested by FT-IR (Cary 5000, Agilent, Malaysia) with the scanning range of $400 \sim 4000 \mathrm{~cm}^{-1}$.

\subsubsection{Determination of molecular weight and molecular weight distribution}

The sample was dissolved in $0.1 \mathrm{~mol} / \mathrm{L}$ sodium nitrite buffer solution to obtain retanning agent solution with a concentration of $2 \%$. The molecular weights and polydispersity indices (PDI) of GAMP, MTA and P were determined by gel permeation chromatography (GPC).

\subsubsection{Zeta potential}

The sample was dissolved in pure water to obtain retanning agent solution with a concentration of $0.5 \%$. The $\mathrm{pH}$ values of solutions were adjusted with $0.1 \mathrm{~mol} / \mathrm{L}$ $\mathrm{NaOH}$ or $0.1 \mathrm{~mol} / \mathrm{L} \mathrm{HCl}$, and Zeta potentials of solutions under different $\mathrm{pH}$ were measured by nanoparticle surface potential analyzer (ZS90, Malvern, Britain).

\subsection{Application}

\subsubsection{Leather productive process}

A variety of retanning agents (GAMP, MTA and P) synthesized in this work were applied to the same wet-blue (chrome tanned) leather. The sampling method in the experiment was shown in Fig. 1.

The specific operation was shown in Table 1 . In the experiment, the chemicals dosage depended on the weight of wet-blue leather. Wastewater was separately collected in retanning and dyeing processes during draining out.

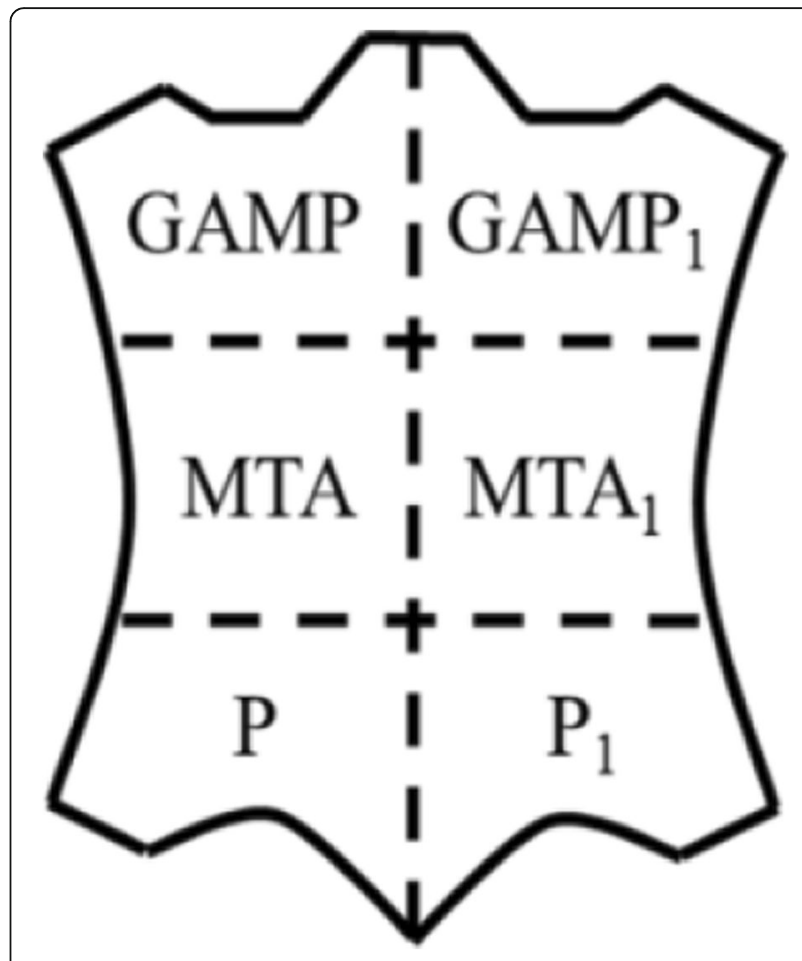

Fig. 1 The sampling method

\subsubsection{Free formaldehyde content}

2.3.2.1 Free formaldehyde content of leather The free formaldehyde content of the leather was determined by spectrophotometry [24] with EN ISO 17226 standard. Firstly, free formaldehyde existing in the leather was extracted by $0.1 \%$ sodium dodecyl sulphonate solution for 60 min with oscillation and then the supernatant was collected by filtration. Then $5 \mathrm{~mL}$ supernatant reacted with $5 \mathrm{~mL}$ acetylacetone which were dissolved in ammonium acetate and glacial acetic acid miscible solution. Afterwards, the absorbance at $412 \mathrm{~nm}$ was recorded. All the samples were tested in triplicate and the mean value was used as the experimental result.

2.3.2.2 Free formaldehyde content of retanning agent After diluting the retanning agent, the absorbance of solutions was determined according to the above method.

\subsubsection{Analysis of thermal property}

The thermal stability of leather was determined by differential scanning calorimeter (Netzsch DSC 200 PC, Germany). The samples $(5 \mathrm{mg}$ ) were accurately weighed and sealed into alumina pans, and then heated from 30 to $200^{\circ} \mathrm{C}$ at a heating rate of $5^{\circ} \mathrm{C} / \mathrm{min}$ in $\mathrm{N}_{2}$ atmosphere. 
Table 1 Specific operation of conventional and experimental processes ${ }^{a}$

\begin{tabular}{|c|c|c|c|c|c|}
\hline Process & Chemicals & Dosage (\%) & Temperature $\left({ }^{\circ} \mathrm{C}\right)$ & Time (min) & Remarks \\
\hline \multirow[t]{3}{*}{ Rewettion } & Water & 200 & 45 & 120 & \\
\hline & Degreasing agent & 0.2 & & & \\
\hline & Wetting agent & 0.5 & & & \\
\hline \multicolumn{6}{|l|}{ Wash, drain } \\
\hline \multirow[t]{4}{*}{ Neutralization } & Water & 150 & 30 & 30 & \\
\hline & Sodium formate & 1.0 & & & \\
\hline & Neutralizing syntan & 2.0 & & & \\
\hline & Sodium bicarbonate & 1.5 & & $30 \times 2$ & pH: 5.5+; Drain \\
\hline \multicolumn{6}{|l|}{ Wash, drain } \\
\hline \multirow[t]{3}{*}{ Retanning } & Water & 100 & 30 & $15 \times 4+60$ & \\
\hline & Retanning agents & 10 & & & \\
\hline & Formic acid & 1.0 & & $20 \times 3+30$ & pH: 3.8 \\
\hline \multicolumn{6}{|c|}{ Stop drums for the night (drain) } \\
\hline \multirow[t]{4}{*}{ Dyeing and Fatliqouring } & Water & 150 & 50 & & \\
\hline & Sodium bicarbonate & & & & $\mathrm{pH}: 5.0$ \\
\hline & Black dye & 3 & & 40 & \\
\hline & Synthetic & 12 & & 60 & \\
\hline Fixing & Formic acid & 2.0 & & $20 \times 3$ & pH: 3.5; Drain \\
\hline
\end{tabular}

${ }^{a}$ : Sodium bicarbonate was dissolved in 20 times water; retanning agent and formic acid were respectively diluted with 10 times water; the fatliquoring agent was emulsified with hot water

\subsubsection{Analysis of assistant-dyeing properties}

2.3.4.1 Leather surface color depth $(K / S)$ All leather samples were conditioned for $48 \mathrm{~h}$ in standard atmosphere $\left(65 \% \pm 2 \% \mathrm{RH}, 20 \pm 2{ }^{\circ} \mathrm{C}\right)$ before test. The absorption coefficient $\mathrm{K}$ and the scattering coefficient $\mathrm{S}$ were measured by X-Rite (ci7800, USA), and then the K/S value was used to explain the surface color depth of the leather.

2.3.4.2 Color fastness to cycles of to-and-fro rubbing (wet/dry) Color fastness to cycles of to-and-fro wet or dry rubbing was tested according to standards $\mathrm{QB} / \mathrm{T}$ 1327-1991. Under a certain pressure, the whiteness of the interlining cloth (white) would change when the color transferred from the leather surface to the interlining cloth during the reciprocating friction process of the interlining cloth on the leather surface. X-Rite was used to measure the whiteness of the interlining cloth to evaluate the color fastness of the leather.

2.3.4.3 Color fastness to washing (discoloration) Leather samples were soaped according to ISO 105-c062010. Then the blackness of leather before and after soaping was determined by X-Rite. The washing fastness was evaluated by contrasting the blackness of leather before and after soaping.

\subsubsection{Leather properties}

2.3.5.1 Thickening rate All leather samples were conditioned for $48 \mathrm{~h}$ in standard atmosphere $(65 \% \pm 2 \% \mathrm{RH}$, $20 \pm 2{ }^{\circ} \mathrm{C}$ ) before test. Leather sample were marked before retanning. Thickness of markers before and after retanning was measured and recorded as $T_{0}(\mathrm{~mm})$ and $T_{1}(\mathrm{~mm})$. Thickening rate $\left(T_{\mathrm{r}}\right)$ is calculated according to the formula:

$$
T_{\mathrm{r}}=\frac{T_{1}-T_{0}}{T_{0}} \times 100 \%
$$

2.3.5.2 Gain of leather A square $(10 \mathrm{~cm} \times 10 \mathrm{~cm})$ was marked on wet blue leather before retanning, and then the area of the marked sign after retanning was measured. Gain of leather is the ratio of area after and before retanning.

2.3.5.3 Physical-mechanical property After cut in standard molds, all leather samples were conditioned for $48 \mathrm{~h}$ in standard atmosphere $\left(65 \% \pm 2 \% \mathrm{RH}, 20 \pm 2{ }^{\circ} \mathrm{C}\right)$ before test. For effectiveness of measurement, six samples were obtained along the lines vertical and parallel to the spine, respectively. According to the standard ISO 3376:1976, the physical and mechanical properties of 
leather were measured by a universal testing machine (AI-3000, Gotech Testing Machines Limited, China).

2.3.5.4 Softness The softness of the leather sample was examined by the softness tester according to the standard procedure (GT303, Gotech Testing Machines Limited, China).

\subsubsection{Environmental impact assessment}

The biodegradation of retanning wastewater was estimated by biochemical oxygen demand $\left(\mathrm{BOD}_{5}\right)$ and chemical oxygen demand (COD), which were tested according to the Chinese standards (HJ 505-2009 and GB/ T 11914-1989).

\section{Results and discussion}

\subsection{Amination degree}

Mannich modification degree was expressed by amination degree. $[\mathrm{CHO}] / \mathrm{DEM}$ value affected the amination degree, which represented the introduction amount of amino group [25, 26]. Figure 2 showed that the amination degrees of Mannich base polymers prepared under different ratio of aldehyde group to amine ([CHO]/ DEM) with $45^{\circ} \mathrm{C}$ and $4 \mathrm{~h}$. As shown in Fig. 2, the maximum value appeared when the ratio of aldehyde group to amine ([CHO]/DEM) was $0.8: 1$. Therefore, the optimum preparation ratio of aldehyde group to amine ([CHO]/DEM) of Mannich base polymer was 0.8.

\section{$3.2{ }^{1} \mathrm{H}$ NMR spectra}

The chemical structures of the GAMP, MTA and P were examined by ${ }^{1} \mathrm{H}-\mathrm{NMR}$. As shown in Fig. 3, the proton peaks of $-\mathrm{CH}_{2}-$ (a) and $-\mathrm{CH}-$ (b) on the main chain of the polymer were found at 1.48 and 2.06 $\mathrm{ppm}$, respectively, and the solvent peak was found at $\delta=4.69 \mathrm{ppm}$. Additionally, the peak at $\delta=3.00 \mathrm{ppm}$ in

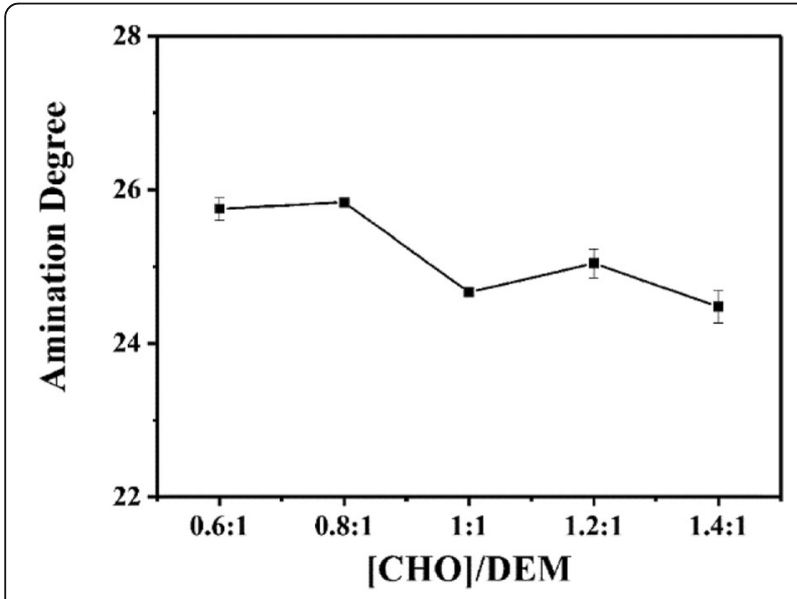

Fig. 2 The amination degrees of Mannich base polymers prepared under different ratio of [CHO]/DEM
GAMP was the triple peak of $-\mathrm{N}-\mathrm{CH}_{2}-(\mathrm{d})$, the peak at $\delta=3.70 \mathrm{ppm}$ was the triple peak of $\mathrm{OH}-\mathrm{CH}_{2-}$ (e). The peak at $\delta=2.82 \mathrm{ppm}$ was the triple peak of methylene (c), which proved that Mannich reaction occurred and there was no obvious peak near 2.82 $\mathrm{ppm}$, indicated that only one methylene formed in Mannich reaction; that was to say, for most of GAMP, only one - $\mathrm{CHO}$ group was participated in Mannich reaction and two - $\mathrm{CHO}$ groups were participated in a few cases. The peak of $-\mathrm{OH}$ and $-\mathrm{CH}_{2}-$ linking to carbonyl group might coincide with the solvent peak and (b), respectively.

\subsection{FT-IR spectra}

The chemical structures of GAMP, MTA and P were performed by FT-IR spectra. As shown in Fig. 4, the absorption peak near $3450 \mathrm{~cm}^{-1}$ was the stretching vibration absorption peak of $-\mathrm{NH}-$, which coincided with the absorption peak of - $\mathrm{OH}$ on diethanolamine. The absorption peaks at $2930 \mathrm{~cm}^{-1}$ and $2890 \mathrm{~cm}^{-1}$ were the stretching vibration peaks of $-\mathrm{CH}_{2}-$ and $-\mathrm{CH}-$, respectively. The absorption peak at $2250 \mathrm{~cm}^{-1}$ was the characteristic absorption peak of $-\mathrm{CN}$. The absorption peak at $1667 \mathrm{~cm}^{-1}$ was the stretching vibration peak of $\mathrm{C}=\mathrm{O}$. The absorption peak at $1570 \mathrm{~cm}^{-1}$ was the deformation vibration of $\mathrm{N}-\mathrm{H}$ in -CO-NH-. Furthermore, the stretching vibration absorption of $\mathrm{C}-\mathrm{O}$ bond of primary alcohol in Mannich modified product appeared at $1062 \mathrm{~cm}^{-1}$ indicated the successful occurrence of Mannich reaction.

\subsection{Analysis of molecular weight and molecular weight distribution}

The molecular weights of GAMP, MTA and P were shown in Table 2. Due to the difference in the gap between the collagen fibers, different molecular weights of polymers were of benefit to improve the retanning effect. On the one hand, the lower molecular weight components $(1000 \sim 5000)$ could permeate into the gap between the collagen fibers and active groups of polymers could form the covalent crosslinks with the various functional groups of collagen fibers. On the other hand, the higher molecular weight components $(>5000)$ had a good filling effect. Compared with MTA and P, GAMP had wider molecular weight distribution and possessed better permeability and fullness. Meanwhile, as shown in Table 2, the percentage of high molecular weight components in GAMP $(\mathrm{Mn}=455,747)$ was only $~ 2.63 \%$ and the percentage of lower molecular weight components was $\sim 97.34 \%$. Combination with the result of ${ }^{1} \mathrm{H}-\mathrm{NMR}$, it can be inferred that the lower molecular weight components because only one - $\mathrm{CHO}$ group was participated in Mannich reaction. 


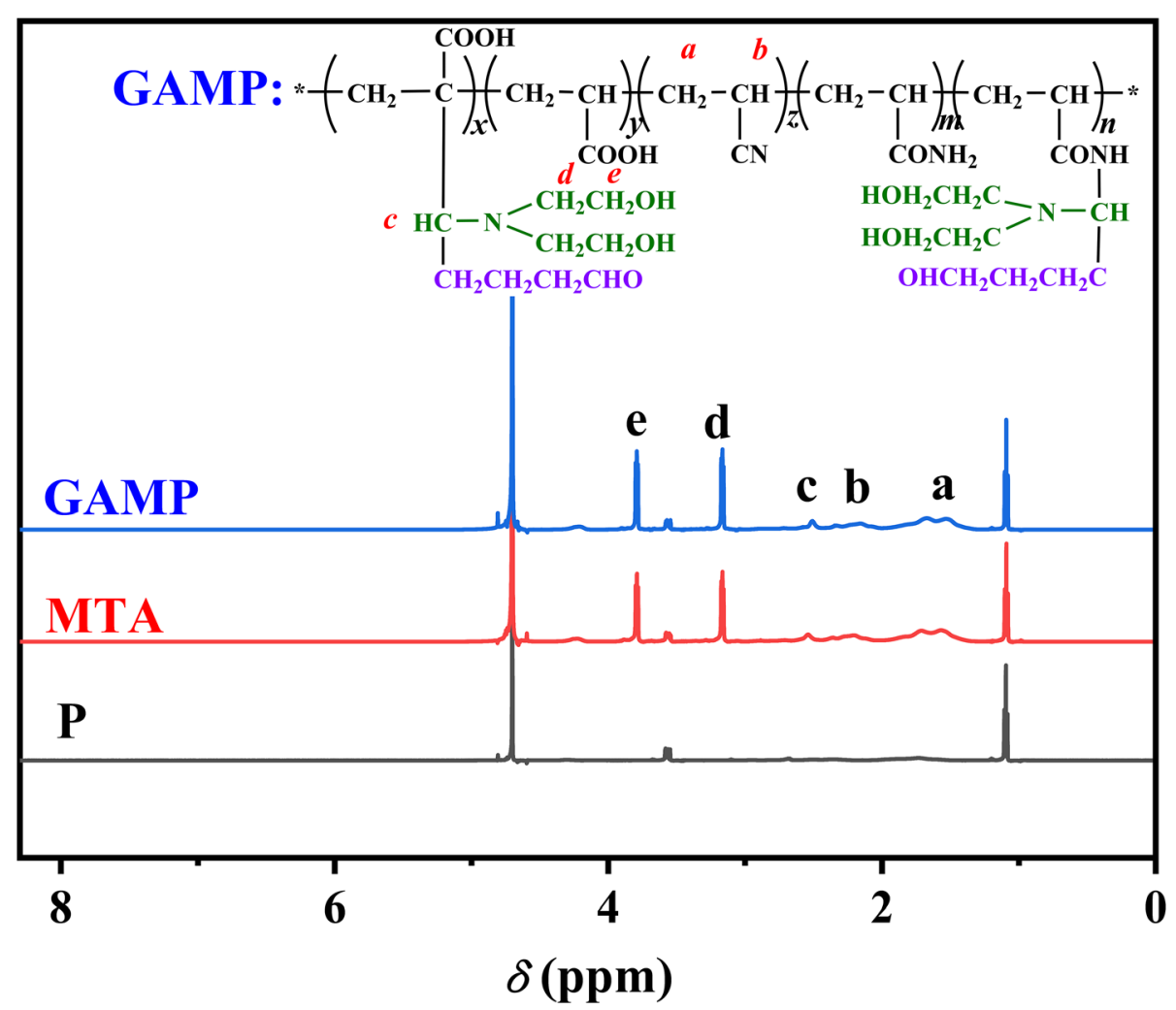

Fig. $3^{1} \mathrm{H}-\mathrm{NMR}$ spectra of the $\mathrm{P}, \mathrm{GAMP}$ and MTA

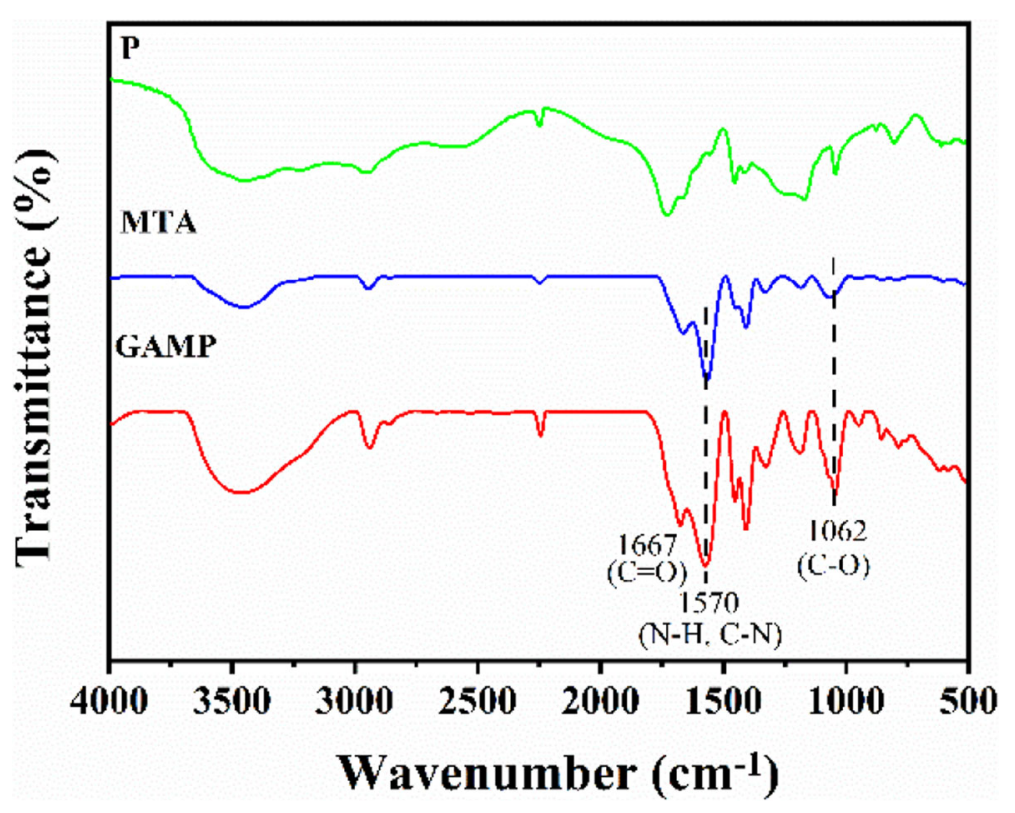

Fig. 4 FT-IR spectra of the P, GAMP and MTA 
Table 2 GPC results of GAMP, MTA and P

\begin{tabular}{llllllll}
\hline Sample & $\mathbf{M}_{\mathbf{n}}$ & $\mathbf{M}_{\mathbf{w}}$ & $\mathbf{M}_{\mathbf{p}}$ & $\mathbf{M}_{\mathbf{z}}$ & $\mathbf{M}_{\mathbf{z}+\mathbf{1}}$ & PDI & Percentages (\%) \\
\hline GAMP & 455,747 & 467,810 & 543,235 & 479,986 & 491,967 & 1.03 & 2.63 \\
& 43,868 & 70,446 & 54,900 & 120,209 & 180,204 & 1.61 & 67.76 \\
& 9620 & 10,898 & 15,784 & 12,040 & 12,956 & 1.13 & 19.24 \\
& 3412 & 3525 & 4115 & 3638 & 3746 & 1.03 & 5.26 \\
MTA & 1835 & 1903 & 2160 & 1967 & 2025 & 1.02 & 5.11 \\
& 97,731 & 190,623 & 292,012 & 251,099 & 285,345 & 1.95 & 94.36 \\
P & 5274 & 6882 & 12,354 & 8289 & 9275 & 1.30 & 5.23 \\
& 1644 & 1679 & 1998 & 1711 & 1739 & 1.02 & 0.41 \\
& 89,133 & 181,898 & 217,080 & 247,345 & 286,180 & 2.04 & 94.69 \\
\end{tabular}

\subsection{Zeta potential}

The zeta potentials of retanning agents as a function of $\mathrm{pH}$ were determined. As shown in Fig. 5, zeta potential for unmodified acylic polymer $(\mathrm{P})$ was negative in the $\mathrm{pH}$ range of 2-7. However, zeta potential for GAMP and MTA were positive as $\mathrm{pH}$ value was lower than 3, and the isoelectric points (pI) were 2.39 and 3.07 for GAMP and MTA, respectively, indicating that the successful introduction of cationic groups.

\subsection{Free formaldehyde content}

The free formaldehyde contents of different retanning agents and corresponding retanned leathers were listed in Table 3. The results showed that raw materials had an obvious effect on the free formaldehyde contents of retanning agents. The free formaldehyde contents in the retanning agent modified by Mannich with formaldehyde (MTA) was $372.22 \mathrm{mg} / \mathrm{kg}$ and outclassed that of unmodified polymer $\mathrm{P}(2.78 \mathrm{mg} / \mathrm{kg})$. However, the free formaldehyde contents of GAMP decreased obviously,

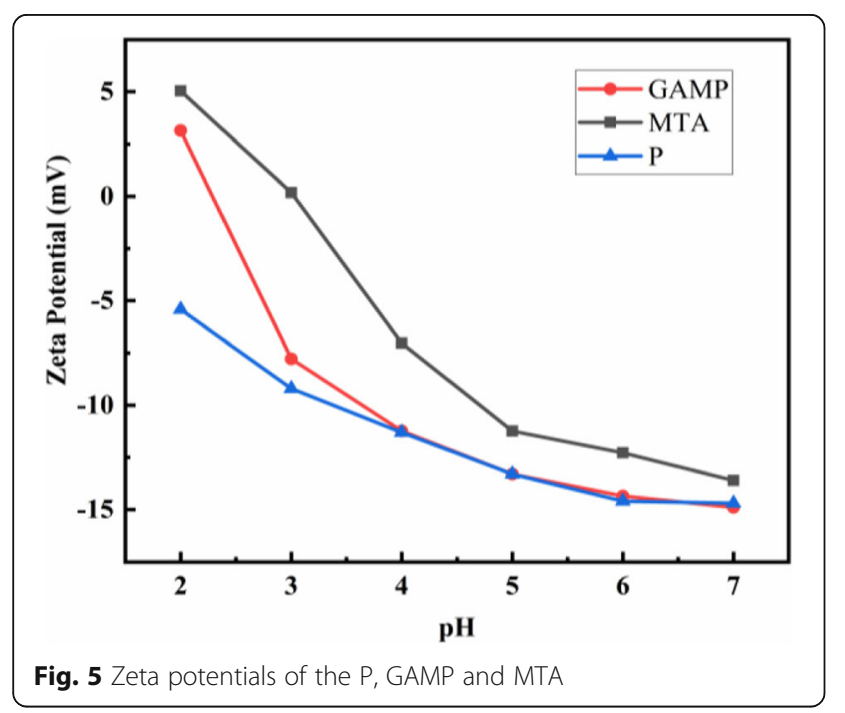

which was only $4.17 \mathrm{mg} / \mathrm{kg}$. Therefore, replacing formaldehyde with glutaraldehyde was significant effectively reduce the free formaldehyde contents of Mannich reaction products.

As shown in Table 3, the free formaldehyde content of leather was more than retanning agents due to the introduction of formaldehyde existing in other chemical materials used in leather making. The free formaldehyde content of leather retanned with MTA was still the highest value $(386.8 \mathrm{mg} / \mathrm{kg})$, which exceeded the limiting value of free formaldehyde content $(150 \mathrm{mg} / \mathrm{kg})$. It was a satisfaction to find that the free formaldehyde content of GAMP-ratanned leather was only $42.01 \mathrm{mg} / \mathrm{kg}$ within the limiting value. The results showed that the problem of formaldehyde was solved by glutaraldehyde substitution.

\subsection{Thermal properties}

Thermal stability of leather was widely used to characterize the retanning effect, which is closely related to the cross-linking degree of retanning agent and leather. The triplex helix structure of uncross-linked collagen in leather was transferred to random coil during denaturation process. Therefore, the thermal stability of leather can be evaluated by the thermal denaturating temperature $\left(T_{\mathrm{d}}\right)$ [27]. Higher denaturation temperature of retanned leather indicates a better thermal stability, which was beneficial to the follow-up leather-making processes. The DSC curves of the leather samples

Table 3 The free formaldehyde contents of different retanning agents and corresponding retanned leathers

\begin{tabular}{lll}
\hline Sample & Concentration $(\mathbf{m g} / \mathbf{k g})$ \\
\cline { 2 - 3 } & Retanning agent & Retanned Leather \\
\hline GAMP & 4.17 & 42.01 \\
MTA & 372.22 & 386.8 \\
P & 2.78 & 41.67 \\
\hline
\end{tabular}


retanned with the different retanning agents were shown in Fig. 6.The peak value of DSC represents the $T_{\mathrm{d}}$ of leather. The $T_{\mathrm{d}}$ value of GAMP-retanned leather reached $120.7^{\circ} \mathrm{C}$, which was higher than those of MTA and P with 117.6 and $115.4{ }^{\circ} \mathrm{C}$.

The increase in denaturation temperature indicated that retanning agent played an important role on the thermal stability of leather. It can be conjectured that this result was attributed to the interaction between retanning agents and collagen in leather, such as coordinate bonds, electrovalent bonds, hydrogen bonds and covalent bonds. Coordinate bonds formed between carboxyl groups in polymer molecule and chromium ions in wet-blue leather. The carboxyl groups, amide groups, cyano groups and tertiary amine groups of retanning agent formed electrostatic interaction and hydrogen bond with the amine groups and carboxyl groups of leather. Aldehyde groups not involved in Mannich reaction covalently bonded with amino groups on collagen fibers. According to ${ }^{1} \mathrm{H}-\mathrm{NMR}$ spectra of GAMP (Fig. 3), the peak at $\delta=$ $2.82 \mathrm{ppm}$ was the triple peak, which belongs to the methylene (c) formed after Mannich reaction of aldehyde group. And there was no obvious peak near $\delta=$ $2.82 \mathrm{ppm}$, indicating that only one methylene formed after Mannich reaction. Meanwhile, as shown in Table 2, the percentage of polymers with high molecular weight $(\mathrm{Mn}=455,747)$ was only $\sim 2.63 \%$ and the weight percent of lower molecular weight polymer was $\sim 97.34 \%$. It can be conjectured that for most of GAMP, only one - $\mathrm{CHO}$ group was participated in Mannich reaction and two - $\mathrm{CHO}$ groups were participated in a few cases. The unreacted aldehyde groups on glutaraldehyde might form the covalent bonds with the amino group on leather during retanning process. Compared with GAMP, MTA and P were unable to form covalent bond with

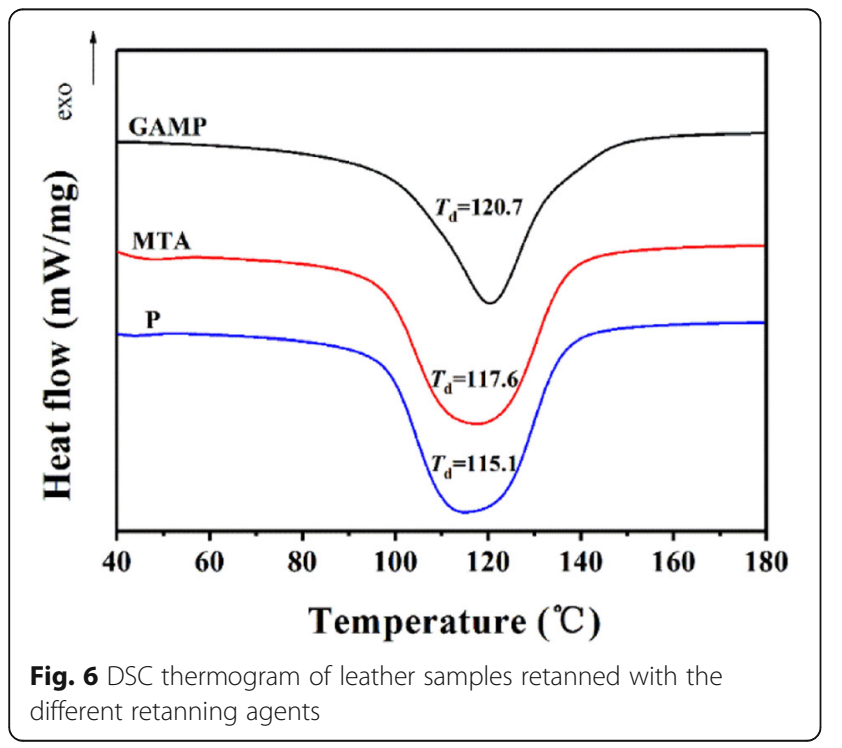

leather due to the absence of free aldehyde groups. Therefore, the $T_{\mathrm{d}}$ value of GAMP-retanned leather was higher than those of MTA-retanned and P-retanned leather. The $T_{\mathrm{d}}$ value of GAMP-retanned leather was higher followed by that of MTA-retanned leather, and that of P-retanned leather was the lowest.

\subsection{Dyeing properties}

GAMP has assistant-dyeing properties might due to its cationic groups. To investigate the assistant-dyeing properties of the GAMP, the wet-blue leather was retanned with retanning agent and subsequently dyed with anionic dye (acid black). The dyed leather should possess uniform penetration and combination, good color fastness under frictional force (rub) and water washing [28]. Through the determination of $\mathrm{K} / \mathrm{S}$, residual dye content in dyeing wastewater, rub fastness and wash fastness, the dyeing properties of leather were explained.

\subsubsection{Dye-uptake}

The K/S value of leather samples retanned with the different retanning agents were taken and shown in Fig. 7. $\mathrm{K} / \mathrm{S}$ value was one of the important indexes for evaluating dyeing performance. The higher the K/S value indicated the darker the surface color of sample and the better the dyeing performance was. The results showed that the K/S value on the surface of the GAMP-treated leathers was higher than the those of MTA-treated and P-treated leathers. The presence of GAMP enhanced the dye-uptake on the leather by providing more cationic groups (amido) for electrostatic interaction with anionic dyes. The assisting-dyeing of GAMP could also be proved by the residual dye content of dyeing wastewater. The residual dye content in dyed wastewater of $\mathrm{P}$ retanned leather was as high as $17.4 \mathrm{mg} / \mathrm{L}$. However, the residual dye contents in dyed wastewater of GAMPretanned and MTA-retanned leather were only about 10 $\mathrm{mg} / \mathrm{L}$, indicating that the absorption and combination of dye in leather was improved by retanning with GAMP.

\subsubsection{Color fastness}

Table 4 showd the blackness of leather before and after washing with soapy water five times to determine the colour fastness to washing of dyed leather and the whiteness of wet or dry interlining cloths rubbed on the dyed leathers. As shown in Table 4, GAMP-retanned leather had the higher blackness after dyeing than MTAretanned and P-retanned leathers, which further indicated that GAMP-retanned leather had a good absorption capacity for dyes. The darkness of GAMP-retanned leathers after dyeing was still the highest after washing. The results showed that the GAMP-retanned leather after dyeing showed less decolorization than P-retanned 


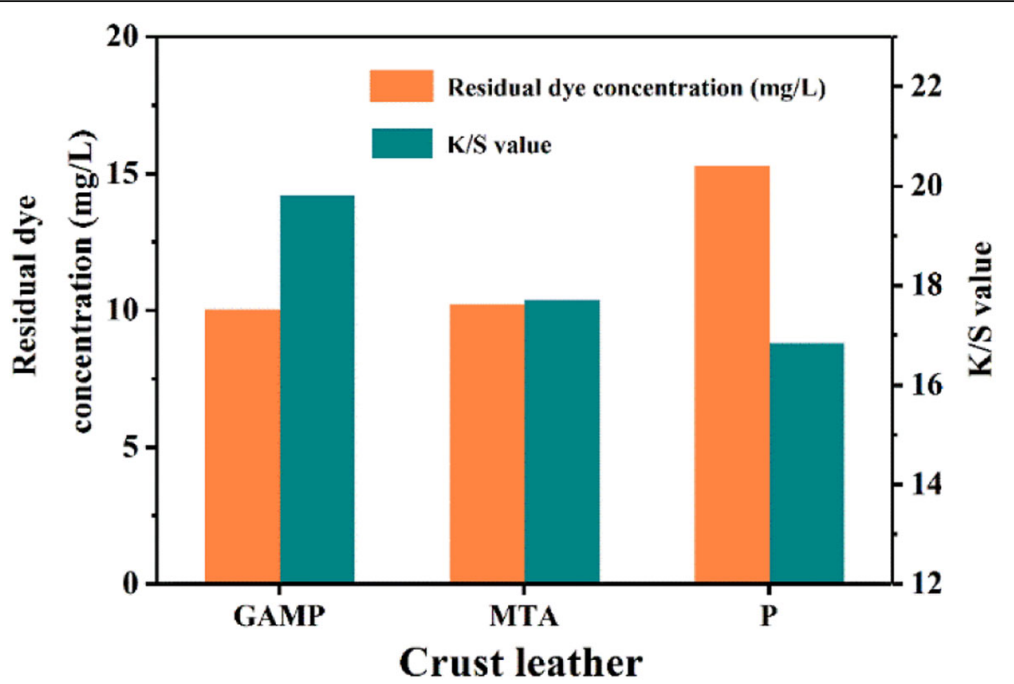

Fig. 7 K/S value of leather samples retanned with the different retanning agents and residual dye concentration in dyeing wastewater of the retanned leathers

leather, meaning that GAMP had better washing fastness. The main factor was the cationic group in the GAMP, resulting in the more adsorption and fixation of dye molecules on the leather by electrostatic action.

Color fastness of dyed leather toward rub was analyzed by using crockmeter with to-and-fro motion. The whiteness of interlining cloths decreases with the increase of color transfer. The higher the whiteness indicated the better the rubbing fastness of dyed leather. As expected, after rubbing with the interlining cloths, dyed GAMPretanned leather showed comparatively less color transfer than dyed MTA-retanned and P-retanned leathers. The high stability toward color fastness might be attributed to abundant electrostatic attraction between anionic dyes and cationic amido groups of Mannich base polymers in the leathers.
As we all know, leather is amphoteric substance. It had been reported that the isoelectric point of blue wet leather was between 7.7 and 7.9 [29]. In the retanning process, $\mathrm{pH}$ of the bath was 5 and the leather surface was electropositive, which was conducive to the penetration and combination of anionic materials (P and Mannich base polymers). The surface positive electricity of P-retanned leather decreased, the penetration and combination of anionic dyes in dyeing process were inhibited due to electrostatic repulsion. Therefore, the color of the leather was not full and poor fastness. Although the surface positive charge of Mannich base polymer-retanned leather decreased, it also brought partial positive charge. The positive charge on leather and retanning agents formed an electrostatic attraction with the anionic dye, leading to more dye molecules were absorbed and fixed

Table 4 Blackness of leather before and after washing with soapy water five times and whiteness of wet and dry interlining cloths rubbed on the dyed leathers

Blackness

Whiteness

Sample

Before washing After washing Dry rubbing Wet rubbing

GAMP

163.82

MTA

161.99

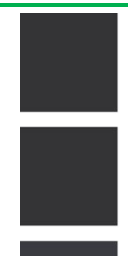

158.25

P

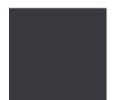

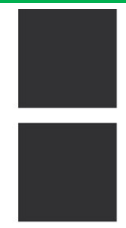

161.4

169.92

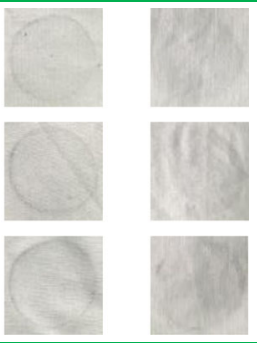

165.63

166.6

162.29 


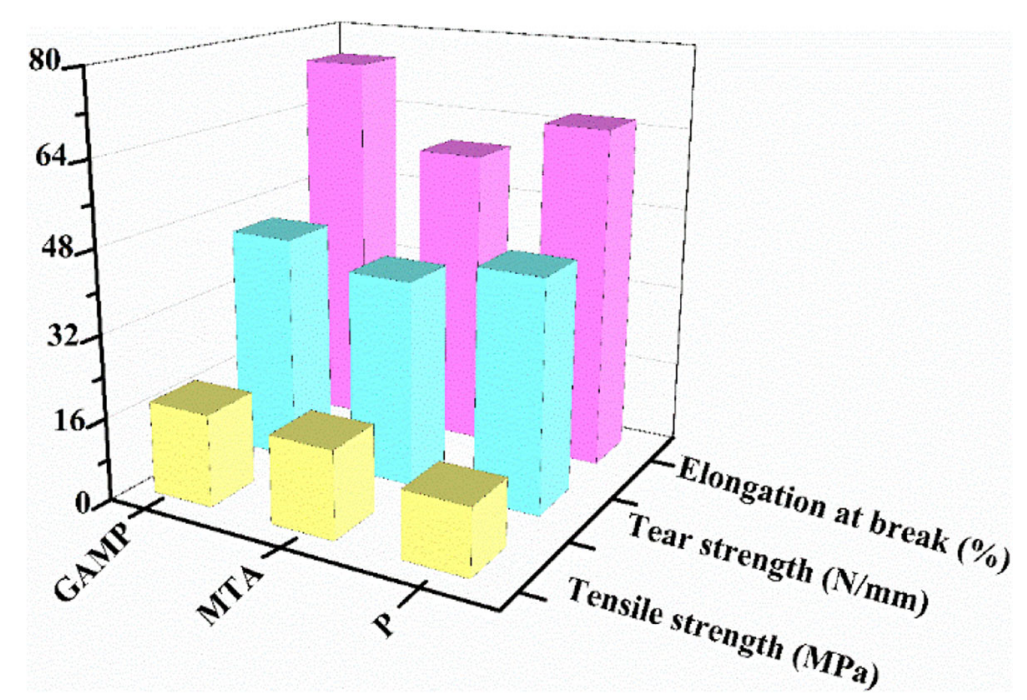

Fig. 8 Physical and mechanical properties of leather samples retanned with the different retanning agents

to leather. In summary, GAMP can not only penetrate and bind well in the leather, but also promote the penetration and binding of anionic dyes.

\subsection{Physical-mechanical properties of leathers}

Figure 8 displays the physical-mechanical properties of leather samples retanned with the different retanning agents. Compared with MTA-retanned and P-retanned leathers, the increase in the elongation at break and tensile strength of GAMP-retanned leathers was higher and the tear strength had an unobvious change. This might be due to the fact that the introduction of cationic groups through Mannich reaction with GAMP, which had more active groups to interact with leather. Additionally, GAMP contained some unreacted aldehyde group, which could form cross-linking with leather [8].

Therefore, the interaction between leather and GAMP was stronger and the collagen fiber structure of leather retanned with GAMP was more orderly, resulting in the better mechanical properties of GAMP-retanned leather.

\subsection{Organoleptic properties of leathers}

Figure 9 displayed the organoleptic properties of the retanned leathers. The thickening rate of GAMPretanned leather was higher than that of MTA-retanned or P-retanned leather. The aldehyde group in GAMP

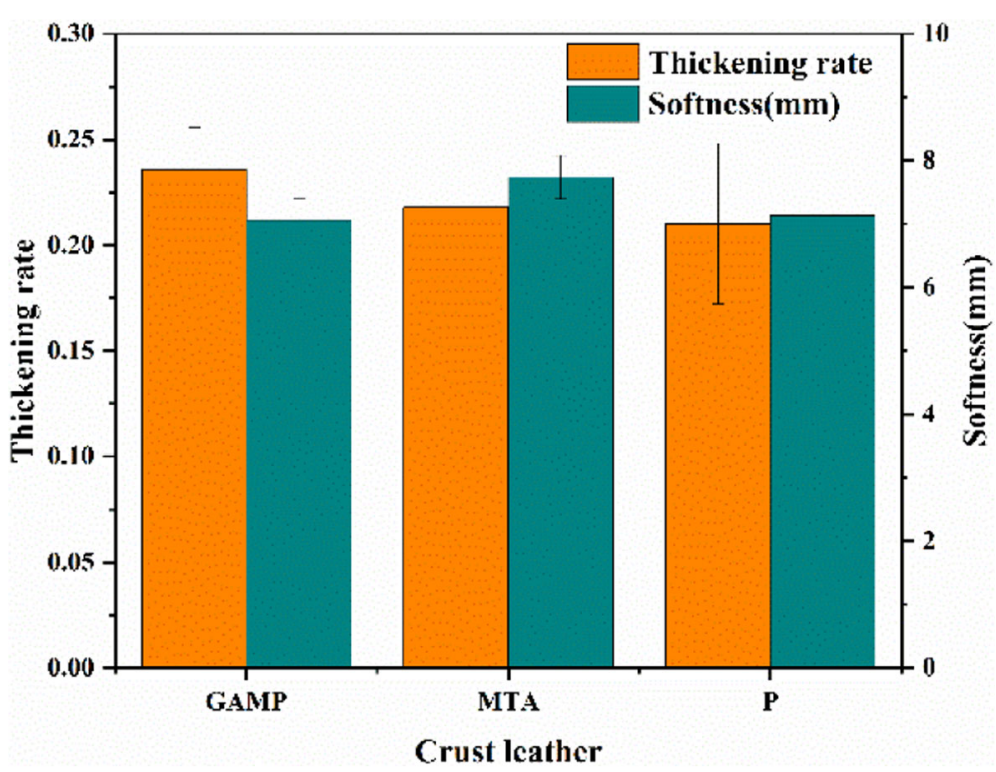

Fig. 9 The organoleptic properties of leathers treated with different retanning agents 
Table 5 Biochemical oxygen demand $\left(\mathrm{BOD}_{5}\right)$ and Chemical oxygen demand (COD) of the wastewater after retanning

\begin{tabular}{llll}
\hline Sample & BOD $_{\mathbf{5}}(\mathbf{m g} / \mathbf{L})$ & COD $(\mathbf{m g} / \mathbf{L})$ & BOD $_{5} / \mathbf{C O D}$ \\
\hline GAMP & 1680 & 5180 & 0.32 \\
MTA & 870 & 2570 & 0.34 \\
P & 1780 & 6330 & 0.28 \\
\hline
\end{tabular}

which was not involved in Mannich reaction could form cross-linking with collagen fibers and fixed collagen fibers, inducing the expansion of fiber gaps. Nevertheless, the softness of GAMP-retanned leather was unchanged due to the inhibition of cross-linking on the motion of collagen fibers [30].

\subsection{Environmental impact assessments}

The parameters chemical oxygen demand (COD) and biochemical oxygen demand $\left(\mathrm{BOD}_{5}\right)$ of the wastewater after the retanning process were characterized. The results of $\mathrm{BOD}_{5}$ and COD were presented in Table 5 . The $\mathrm{COD}$ and $\mathrm{BOD}_{5}$ values of the wastewater after retannning with Mannich base polymers were higher than that of the wastewater after retannning with acrylic polymer. Incomplete Mannich reaction would lead to the increase of organic low molecular weight residues in the Mannich base polymers, which might be the reason for the high $\mathrm{BOD}_{5}$ and $\mathrm{COD}$ values.

However, the $\mathrm{BOD}_{5}$ and $\mathrm{COD}$ values of the wastewater after retannning with Mannich base polymer GAMP were lower than that of MTA. The reason might be that the active aldehyde groups of GAMP bonded to collagen and enhance its fixation in leather. The $\mathrm{BOD}_{5} / \mathrm{COD}$ value of the wastewater after retanning by MTA was lower than 0.30, illuminated that the wastewater was non-biodegradable. However, the wastewater after retanning by GAMP was biodegradable confirmed by the fact that the $\mathrm{BOD}_{5} / \mathrm{COD}$ values was higher than 0.30 [31].

\section{Conclusions}

In this work, a kind of Mannich base polymer GAMP with low free formaldehyde content was prepared and applied in the retanning of leather. GAMP was an environmentally friendly and easily biodegradable retanning agent, it could be used retanning application with better assistant-dyeing characteristics. The leather treated by GAMP exhibited better performance, such as color fastness, gloss uniform, thermal stability, fullness and physical and mechanical properties. It indicated that glutaraldehyde as an alternative to formaldehyde was available in Mannich reaction, and this method could also be used for material preparation in other industries (papermaking, oilfield, water treatment, etc.).

\section{Acknowledgements}

This work was financially supported by the Key Program of National Natural Science Foundation of China (No. 21838007) and National Natural Science Foundation of China (No. 21706151).

\section{Authors' contributions}

JianZhong Ma: conception of the work, drafting the manuscript, substantively revision of the manuscript. Qiwu Liu: characterization of the retanning agent and materials. Mengxin Wu: preparation and application of retanning agent. Zhenhua Tian: conception of the work, analysis and interpretation of data. All authors have read and approved the submitted version (and any substantially modified version that involves the author's contribution to the study). All authors have agreed both to be personally accountable for the author's own contributions and to ensure that questions related to the accuracy or integrity of any part of the work, even ones in which the author was not personally involved, are appropriately investigated, resolved, and the resolution documented in the literature.

\section{Funding}

The financial support of this study was from the Key Program of National Natural Science Foundation of China (No. 21838007) and National Natural Science Foundation of China (No. 21706151).

\section{Availability of data and materials}

The datasets used and analyzed during the current study are available from the corresponding author on reasonable request.

\section{Declarations}

Ethics approval and consent to participate

Not applicable.

\section{Consent for publication}

Not applicable.

\section{Competing interests}

The authors declare that they have no competing interests.

\section{Author details}

${ }^{1}$ College of Bioresources Chemical and Materials Engineering, Shaanxi University of Science \& Technology, Xi'an 710021, Shaanxi, China. ${ }^{2}$ College of Chemistry and Chemical Engineering, Shaanxi University of Science \& Technology, Xi'an 710021, Shaanxi, China.

Received: 8 January 2021 Accepted: 20 July 2021

Published online: 15 October 2021

\section{References}

1. Tang $K Y$, Zheng $X J$, Yang $M$, et al. Influence of retanning on the adsorption capacity of water on cattlehide collagen fibers. J Am Leather Chem As. 2009;104(11):367-74.

2. Zarlok J, Kowalska M, Smiechowsk K. Effect of the type of retanning on hygienic properties of crust leathers. J Soc Leath Tech Ch. 2017;101(1):21-6.

3. Bao Y, Ma JZ. Progress of acrylic polymer tanning agent. China Leather. 2011:40(15):51-5.

4. Jin $L Q$, Wang $Y L$, Zhu DY, et al. Effect of amphoteric acrylic Retanning agent on the physical properties of the resultant leather. Adv Mater Res. 2011: 284-6 1925-1928.

5. Wu SY, Gu LS, Huang ZH, Sun Q, Chen H, Ling J, et al. Intrafibrillar mineralization of polyacrylic acid-bound collagen fibrils using a twodimensional collagen model and Portland cement-based resins. Eur J Oral Sci. 2017;125(1):72-80. https://doi.org/10.1111/eos.12319.

6. Abbott AP, Alaysuy O, Antunes APM, Douglas AC, Guthrie-Strachan J, Wise WR. Processing of leather using deep eutectic solvents. ACS Sustain Chem Eng. 2015;3(6):1241-7. https://doi.org/10.1021/acssuschemeng.5b00226.

7. Wang YN, Huang WL, Zhang HS, et al. Surface charge and isoelectric point of leather: a novel determination method and its application in leather making. J Am Leather Chem As. 2017;7(112):224-31.

8. Song Y, Wang YN, Zeng YH, et al. Quantitative determinations of isoelectric point of Retanned leather and distribution of Retanning agent. J Am Chem Soc. 2018;113:232-8. 
9. Ramalingam S, Jonnalagadda RR. Tailoring nanostructured dyes for auxiliary free sustainable leather dyeing application. ACS Sustain Chem Eng. 2017; 5(6):5537-49. https://doi.org/10.1021/acssuschemeng.7b00896.

10. Hussain G, Ather M, Khan MUA, Saeed A, Saleem R, Shabir G, et al. Synthesis and characterization of chromium (III), Iron (II), copper (II) complexes of 4amino-1-(p-Sulphophenyl)-3-methyl-5-pyrazolone based acid dyes and their applications on leather. Dyes Pigments. 2016;130:90-8. https://doi.org/10.1 016/j.dyepig.2016.02.014.

11. Jia L, Ma JZ, Gao DG, Lyu B, Zhang J. Application of an amphoteric polymer for leather pickling to obtain a less total dissolved solids residual process. J Clean Prod. 2016;139:788-95. https://doi.org/10.1016/j.jclepro.2016.08.097.

12. Jia L, Ma JZ, Gao DG, Lyu B, Cheng L. Facile preparation approach of nanocomposite based on water-soluble polymer and layered double hydroxides for the enhancement of leather dyeing. Appl Clay Sci. 2018;152: 22-8. https://doi.org/10.1016/j.clay.2017.10.017.

13. Tramontini M, Angiolini L, Ghedini N. Mannich bases in polymer chemistry. Polymer. 1988;29(5):771-88. https://doi.org/10.1016/0032-3861(88)90132-2.

14. El-Hamshary H, Assubaie FN. Synthesis of cationic and ampholytic starch graft acrylamide and their aqueous salt absorption. J Macromol Sci A. 2011; 48(6):454-61. https://doi.org/10.1080/10601325.2011.573334.

15. Mendis GP, Hua I, Youngblood JP, et al. Enhanced dispersion of lignin in epoxy composites through hydration and mannich functionalization. J Appl Polym Sci. 2015;132(1):41263.

16. Joshi NS, Whitaker LR, Francis MB. A three-component Mannich-type reaction for selective tyrosine bioconjugation. J Am Chem Soc. 2004;126(49): 15942-3. https://doi.org/10.1021/ja0439017.

17. Ma JZ. The study on multiple-functional tanning agent-MTA. Leather Sci Eng. 1994;3:12-5.

18. Yang HX, Yang ZS, Ma JZ. Study on characterization and application of modified polymer tanning agent with Mannich reaction. Leather Chemicals. 2000;4:6-10.

19. Tomatis L. Chemical agents and related occupations. IARC: France; 2012.

20. Dixit $\mathrm{S}$, Yadav $\mathrm{A}$, Dwivedi $\mathrm{P}$, et al. Toxic hazards of leather industry and technologies to combat threat: a review. J Clean Prod. 2015;87(1):39-49. https://doi.org/10.1016/j.jclepro.2014.10.017.

21. Li F, Wang QJ. Produce and control of formaldehyde in leather. Leather Chem. 2011;28(3):30-3.

22. Bai YL, Liu NP, Cui ZH, et al. Screening and researching of aldehyde in Mannich staining. J Zhejiang Sci-Tech Univ (Natural Sciences). 2017;3(37): 336-42.

23. Song $H$, Wu D, Zhang RQ, Qiao LY, Zhang SH, Lin S, et al. Synthesis and application of amphoteric starch graft polymer. Carbohyd Polym. 2009;78(2): 253-7. https://doi.org/10.1016/j.carbpol.2009.03.027.

24. Yuan $\mathrm{HC}$, Chen $\mathrm{H}$. Formaldehyde contents research of several aldehyde tannages and their modification products. Leather Sci Eng (Chinese). 2013; 23(02):38-41+47.

25. Cai Y J, Su W S, Navik R, et al. cationic modification of ramie fibers in liquid ammonia. Cellulose. 2018; 25(8): 4463-4475, doi: https://doi.org/10.1007/s1 0570-018-1905-1.

26. Fang KJ, Zhao HX, Li JZ, et al. Salt-free dyeing of cotton fabrics modified with cationic copolymer nanospheres using an acid dye. Fibers Polymers. 2017;18(2):400-6. https://doi.org/10.1007/s12221-017-6541-0.

27. Lyu B, Chang R, Gao DG, et al. Chromium footprint reduction: nanocomposites as efficient pretanning agents for cowhide shoe upper leather. ACS Sustain Chem Eng. 2018;8(6):5431-23.

28. Ramalingam S, Sreeram KJ, Rao JR, et al. Organic Nano-colourants: a selffixed, optothermal resistive silica supported dyes for sustainable dyeing of leather. ACS Sustain Chem Eng. 2016;4(5):2706-14. https://doi.org/10.1021/a cssuschemeng.6b00218.

29. Sun QY, Wang YN, Liao XP. SDBS adsorption method: a new method for determination of isoelectric point of skin and leather. China Leather. 2013; 42(1):9-13.

30. Sang J, Zheng $C B$, Qiang XH. Development of aldehyde and its derivatives tanning agents. Leather Chem. 2009;26(3):19-23.

31. Liao J, Yang L, Grashow J, Sacks MS. Molecular orientation of collagen in intact planar connective tissues under biaxial stretch. Acta Biomater. 2005; 1(1):45-54. https://doi.org/10.1016/j.actbio.2004.09.007.

\section{Publisher's Note}

Springer Nature remains neutral with regard to jurisdictional claims in published maps and institutional affiliations.

\section{Submit your manuscript to a SpringerOpen ${ }^{\circ}$ journal and benefit from:}

- Convenient online submission

- Rigorous peer review

- Open access: articles freely available online

- High visibility within the field

- Retaining the copyright to your article

Submit your next manuscript at $\boldsymbol{\nabla}$ springeropen.com 